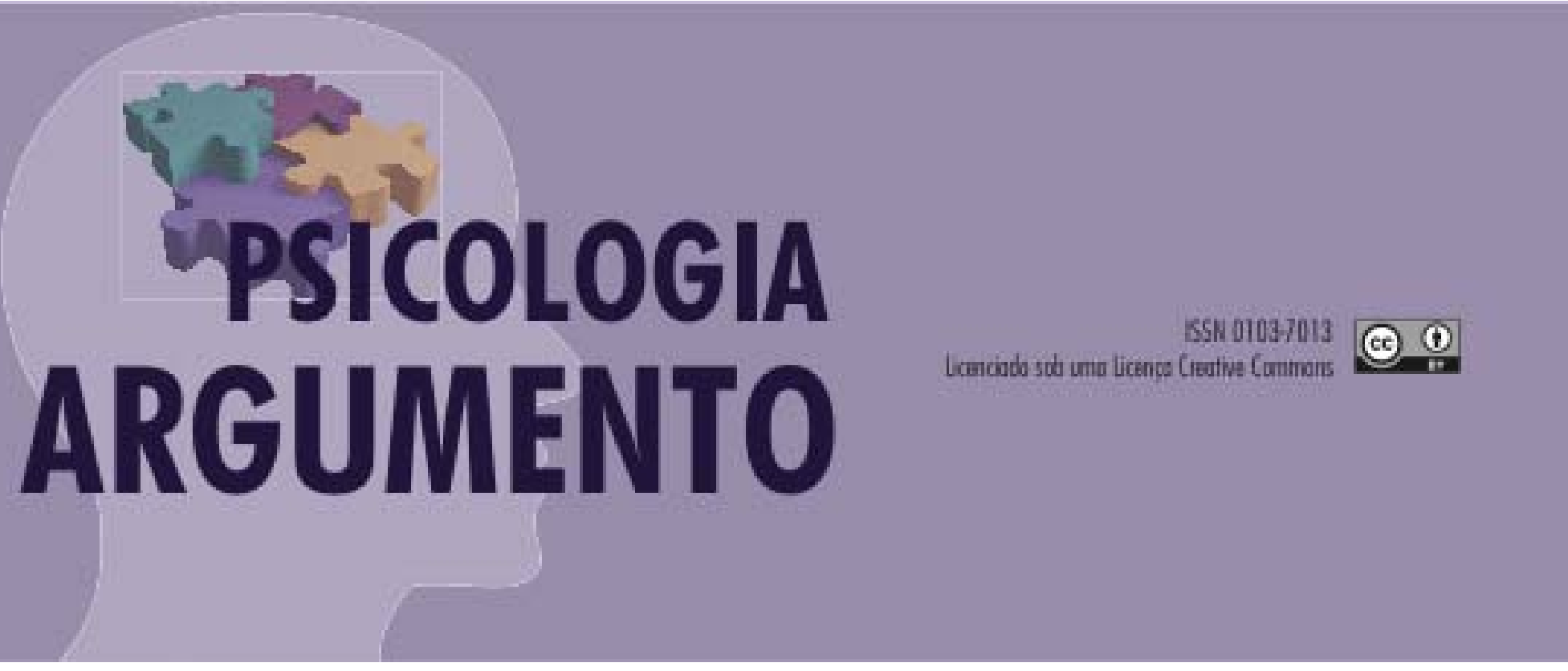

doi: http://dx.doi.org/10.7213/psicolargum.36.91.AO06

\title{
Avaliação de grupos de promoção da saúde no envelhecimento: revisão sistemática
}

Evaluation of groups of health promotion in aging: systematic review

\footnotetext{
Pâmela Stafin Dambrosi Felizardo [a]

Adriano Valério dos Santos Azevêdo ${ }^{[b]}$

Denise de Camargo ${ }^{[c]}$

${ }^{[a] P s i c o ́ l o g a . ~ M e s t r e ~ e m ~ P s i c o l o g i a . ~ U n i v e r s i d a d e ~ T u i u t i ~ d o ~ P a r a n a ́ ~-~}$

pamelastafin@hotmail.com

${ }^{[b]}$ Docente do Programa de Mestrado em Psicologia Social e Saúde da Universidade

Tuiuti do Paraná -adrianoazevedopsi@gmail.com

${ }^{[c]}$ Docente do Programa de Mestrado em Psicologia Social e Saúde da Universidade

Tuiuti do Paraná e professora da Universidade Federal do Paraná-

denisedecamargo@uol.com.br
}

\section{Resumo}

Este artigo objetivou apresentar uma revisão sistemática referente a avaliação de grupos de promoção da saúde no envelhecimento. Nas consultas realizadas nas bases de dados da Literatura Latino-Americana e do Caribe em Ciências da Saúde (Lilacs), e Literatura Internacional em Ciências da Saúde (Medline) foram identificados15 artigos, publicados no período de 2012-2016, o que possibilitou a 
construção das seguintes categorias temáticas: oficinas de educação em saúde, práticas recreativas, práticas corporais, e estimulação cognitiva. Nestes estudos, a avaliação de grupos de promoção da saúde focalizou a dimensão dos resultados, os efeitos das intervenções mediante os relatos dos participantes. Verificou-se a predominância da estratégia de avaliação por meio de grupos focais, em seguida os questionários, e em menor proporção os instrumentos quantitativos de estado geral de saúde e qualidade de vida. Os resultados indicaram que a adesão dos participantes nas intervenções possibilitou melhorias na interação social, nos estados emocionais, no autocuidado com a saúde integral, e na construção de estilos de vida saudáveis devido as aplicações dos conhecimentos obtidos nas atividades cotidianas. Nas avaliações quantitativas foram identificadas mudanças positivas no estado geral de saúde e qualidade de vida. Estes resultados indicam a necessidade de avaliar grupos de promoção da saúde, isto possibilita fundamentar práticas baseadas em evidências e promover saúde para que os idosos desenvolvam a cidadania e o protagonismo, aspectos centrais nas propostas das políticas públicas de saúde do Brasil.

Palavras-chave: Idoso. Promoção da saúde. Envelhecimento. Grupo social.

\begin{abstract}
This article want show a review about the evaluation of groups of health promotion in the aging. In the consultation made it based in on data's of Literature of Latin America and Caribbean in Health Science (Lilacs), and International Literature in Health Science (Medline) were identified 15 articles, released between in 20122016, what make possible the construction of the follow categories: Workshop about health education, recreation practices, body practices, and cognitive stimulation. On these studies, the evaluation of the groups of health promotion had focus on the dimension of the results, the effects of the interventions according with the participants reports. Was check it the predominance of the strategies of evaluation by focal groups, and after the questionnaires, and the small proportion the quantitative instruments of general health state and life quality. The results designated that the accession of the participants on the interventions made possible an improvement of the social interaction, emotional states, self-care with the health, and the construction of life styles according with the applications of knowledge learned in the routine activites. In the quantitative evaluations were identified positive changes on the general health state and life quality. These results indicate the necessity of evaluation of groups of health promotion, this make possible instruct practices based in evidences and promote health for aged people develop citizenry, central aspects on the proposes of health public policies of Brazil.
\end{abstract}

Keywords: Elderly. Health promotion. Aging. Social group.

\title{
Resumen
}

Este artículo objetivó presentar una revisión sistemática referente la evaluación de grupos de promoción de la salud en el envejecimiento. En las consultas realizadas en las bases de datos de la Literatura Latinoamericana y del Caribe en Ciencias de la Salud (Lilacs), y Literatura Internacional en Ciencias de la Salud (Medline) fueron identificados15 artículos, publicados en el período de 2012-2016, lo que posibilitó la construcción de las siguientes categorías temáticas: oficinas de educación en salud, prácticas recreativas, prácticas corporales, y estimulación cognitiva. En estos estudios, la evaluación de grupos de promoción de la salud enfocó la dimensión de los resultados, los efectos de las intervenciones mediante los relatos de los participantes. se verificó la predominancia de la estrategia de evaluación por medio de grupos focales, enseguida los cuestionarios, y en menor proporción los instrumentos cuantitativos de estado general de salud y calidad de vida. Los resultados indicaron que la adhesión de los participantes en las intervenciones posibilitó mejorías en la interacción social, en los estados emocionales, en el 
autocuidado con la salud integral, y en la construcción de estilos de vida saludables debido las aplicaciones de los conocimientos obtenidos en las actividades cotidianas. En las evaluaciones cuantitativas fueron identificadas cambios positivos en el estado general de salud y calidad de vida. Estos resultados indican la necesidad de evaluar grupos de promoción de la salud, esto posibilita fundamentar prácticas basadas en evidencias y promocionar salud para que los de edad desarrollen la ciudadanía y el Protagonismo, aspectos centrales en las propuestas de las políticas públicas de salud de Brasil.

Palabras-clave: Ancianos. Promoción de la salud. Envejecimiento. Grupo social.

\section{Introdução}

Até as décadas de 1960 e 1970 os noticiários, as pesquisas e os olhares da sociedade eram direcionados para as demandas e interesses de pessoas jovens. Os idosos eram deixados de lado por serem vistos, na maioria das vezes, como pessoas que estavam na última etapa da vida, assim, eram consideradas incapazes e improdutivas para novas experiências, restando-lhes apenas aguardar os momentos finais de suas vidas (Barros, 2006; Bohm, 2013; Gonçalves, 2015). Por outro lado, a Organização das Nações Unidas (ONU, 2016) informou que o mundo está vivenciando uma transição demográfica, pelo fato de que a população idosa de 900 milhões em 2015 alcançarádois bilhões em 2050 e, dessa forma, haverá mais pessoas idosas no mundo do que crianças. No Brasil, o Instituto Brasileiro de Geografia e Estatística (IBGE, 2013) indicou o crescente número de idosos, em 2010 foram identificadas 19 milhões de pessoas idosas, e a previsão aproximada para 2060 é de 73 milhões. Desta maneira, é necessária a articulação de serviços e políticas públicas para atender as novas demandas para fins de promover saúde nesta etapa da vida.

O crescente número de pessoas idosas é decorrente da diminuição da taxa de fecundidade e de mortalidade (Borges, Campos, \& Silva, 2015), e do aumento da expectativa de vida em virtude do avanço da tecnologia e do desenvolvimento urbano (Ascari, Comiran, Farias, \& Ferreira, 2015). Dessa forma, se antigamente os assuntos relacionados ao envelhecimento eram negligenciados, atualmente 0 tema ganha destaque devido à relevância da longevidade. Existe uma mudança em relação ao significado de velho, considerado aposentado e limitado, para a representação de pessoas que apresentam experiências a serem compartilhadas e que podem planejar sonhos para viver com autonomia e qualidade de vida (Ascari et al., 2015; Barros, 2006; Freitas, Queiroz, \& Sousa, 2010; Goldenberg, 2014).

O aumento da expectativa de vida e a necessidade de manter a independência motivou os setores da saúde e a comunidade científica a se preocuparem com ações que possibilitem o envelhecimento ativo. Segundo a Organização Mundial da Saúde, o envelhecimento ativo representa "o processo de otimização das oportunidades de saúde, participação e segurança, com o objetivo de melhorar a qualidade de vida à medida que as pessoas ficam mais velhas" (OMS, 2005, p.13). A Portaria $n^{\circ}$. 2528, de 19 de outubro de 2006, da Política 
Nacional de Saúde da Pessoa Idosa também cita em suas diretrizes a necessidade da promoção do envelhecimento ativo e saudável (Brasil, 2006). E referente a este ponto, na produção científica é possível identificar reflexões críticas sobre à promoção da saúde e prevenção de doenças para fomentar qualidade de vida (Peyton, Huang, Syvaoja, \& Lohman, 2019). Nesse sentido, ações de promoção da saúde contribuem para fomentar o envelhecimento ativo, a inclusão social, o protagonismo dos idosos, o desenvolvimento de políticas públicas e de estudos científicos.

A promoção da saúde focaliza-se na saúde integral e está ligada a ações individuais e coletivas que consideram o sujeito em sua totalidade (Czeresnia, 2003). A Política Nacional da Saúde da Pessoa Idosa indica a necessidade de ações de promoção da saúde por meio de trabalhos intersetoriais e interdisciplinares, que valorizam a participação da sociedade. Esses trabalhos devem considerar o idoso na perspectiva da integralidade, abordando o sujeito e suas relações no contexto social, para que seja possível o desenvolvimento da autonomia (Brasil, 2006). A Política Nacional da Promoção da Saúde considera que a saúde é produzida no contexto social, dessa forma, a valorização das experiências individuais e coletivas repercute na integralidade do cuidado por meio da humanização e inclusão social (Brasil, 2014).

A participação social dos idosos nos trabalhos em grupo representa uma estratégia para o desenvolvimento de práticas de promoção da saúde com o objetivo de desenvolver autonomia, qualidade de vida, e garantir o exercício da cidadania. O grupo de promoção da saúde é considerado uma forma de intervenção que integra as múltiplas dimensões do conceito de saúde, valoriza o processo grupal, as interações sociais, a coletividade, e o desenvolvimento de ações interdisicplinares (Santos, Ros, Crepaldi, \& Ramos, 2006). Os trabalhos grupais promovem a superação da esfera individual para práticas que valorizam o sujeito no seu contexto, o que inclui a cultura e a realidade social (Freitas, 2013). Góis (2008) ressalta esses aspectos e recomenda para os profissionais da saúde o desenvolvimento de ações focalizadas nas necessidades das pessoas.

Martin-Baró (1989) considera a ideia de grupo na perspectiva da teoria psicossocial e compreende o grupo por meio de três aspectos: a realidade social vivenciada pelas pessoas, a possibilidade de trabalhar com grupos pequenos e grandes, e a valorização da realidade histórica. Dessa forma, um grupo é constituído e representado pela interação mediante as necessidades individuais e coletivas. De maneira semelhante, Lane (2001) utiliza o termo processo grupal ao invés de grupo. Para a autora, um grupo está imerso em um determinado espaço e apresenta demandas que, no decorrer do tempo, resultam na construção de uma identidade que supera o alcance de objetivos comuns; o processo grupal, por sua vez, compreende a relação social que se estabelece para o desenvolvimento da consciência crítica e da autonomia.

Em uma revisão bibliográfica referente a grupos de promoção da saúde com idosos, Sousa e Assis (2012) ressaltaram a importância da metodologia de educação popular em saúde, demonstrando as contribuições das intervenções em grupo para a vida das pessoas e a necessidade de novos estudos que contribuam 
para o avanço dessas práticas. A educação popular citada pelas autoras engloba a visão global do sujeito, valoriza a participação ativa, a cultura local, os diálogos e a reflexão, o que se mostra congruente com as ideias apresentadas pelos autores (Freitas, 2013; Góis, 2008), e pelas políticas públicas, especificamente a Política Nacional de Saúde da Pessoa Idosa (Brasil, 2006), e a Política Nacional de Promoção da Saúde (Brasil, 2014).

Nesse contexto, o desenvolvimento de práticas de promoção da saúde em grupo para pessoas idosas contribui para efetivar princípios de políticas públicas e fomentar ações em diferentes contextos sociais. Um ponto fundamental refere-se a avaliação de programas de promoção da saúde para delimitar o planejamento, acompanhar o processo de execução, e verificar os efeitos das intervencões. Pedrosa (2004) enfatizou a necessidade do planejamento das ações de maneira participativa para que as decisões ocorram de maneira coletiva. A análise das dimensões (estrutura, processo e resultados) dos programas de promoção da saúde tem sido recomendada e representa um modelo sistêmico de avaliação que permite selecionar critérios para verificação sistemática (Donabedian, 1984, 1997). Pesquisadores construíram uma matriz de avaliação focalizada na estrutura, processo e resultados com critérios específicos para avaliação (Oliveira, Ignacio, Moraes-Neto, \& Barata, 2017), o que representa um guia para profissionais de saúde que possibilita articular o desenvolvimento de projetos de promoção da saúde com metodologia para pesquisa e acompanhamento de etapas. Desta maneira, existe a necessidade de o profissional de saúde desenvolver habilidades teóricas, técnicas e de método para o planejamento e execução de projetos de promoção da saúde, ao considerar que a etapa de avaliação será relevante para identificar e acompanhar os resultados obtidos. Isto auxiia a construção de conhecimento científico baseado em evidências para permitir avanços na área pesquisada.

Foram produzidas revisões de literatura sobre promoção da saúde para idosos (Assis, Hartz, \& Valla, 2004; Carvalho, Silva, Figueiredo, Nogueira, \& Andrade, 2015; Ribeiro \& Faustino, 2013; Sousa \& Assis, 2012), especificamente voltadas para a identificação dos projetos que foram realizados (Assis et al., 2004), as temáticas utilizadas nas intervenções (Ribeiro \& Faustino, 2013), os princípios teórico-metodológicos (Sousa \& Assis, 2012), e as intervenções realizadas pelos enfermeiros (Carvalho et al., 2015). Nesses estudos, foi destacada a importância de avaliar as ações educativas, e desta forma, a avaliação de grupos de promoção da saúde no envelhecimentorepresenta uma temática relevantepara sistematizar práticas e propor estratégias de intervenção na área da saúde coletiva por meio da participação social.

A investigação de práticas de promoção da saúde no envelhecimento possibilita contextualizar o processo de planejamento e os resultados obtidos, buscando fomentar as estratégias de avaliação, o que contribui para o desenvolvimento de novos estudos para a construção de práticas baseadas em evidências. Além disso, os estudos sobre avaliação de programas de promoção da saúde representam recursos potencializadores para a operacionalização de aspectos teóricos e práticos, e para promover reflexões sobre políticas públicas 
com o propósito de efetivar princípios norteadores. Nessa perspectiva, o objetivo deste artigo é apresentar uma revisão sistemática referente a avaliação de grupos de promoção da saúde no envelhecimento.

\section{Método}

Este artigo apresenta uma revisão sistemática que, segundo Sampaio e Mancini (2007), consiste em procurar, analisar e explorar o que foi publicado ao longo do tempo sobre um determinado assunto por meio de visão crítica.

As buscas foram realizadas durante o mês de abril de 2017 por meio da Biblioteca Virtual em Saúde (BVS), utilizando as bases de dados Literatura LatinoAmericana e do Caribe em Ciências da Saúde (Lilacs) e Literatura Internacional em Ciências da Saúde (Medline). A recomendação internacional - Preferred Reporting Items for Systematic Reviews and Meta-Analyses (PRISMA - disponível em: www.prisma-statement.org) - foi utilizada no processo de identificação, seleção, elegibilidade e inclusão dos artigos.

\section{Critérios de inclusão/exclusão}

Foram definidos os seguintes critérios de inclusão: artigos empíricos publicados entre o período de 2012 - 2016 no idioma português (Brasil); pesquisas que se referiam a avaliação de grupos de promoção da saúde de pessoas com idade igual ou superior a 60 anos $^{1}$. As buscas foram realizadas por meio da combinação das palavras-chave: Idoso AND Grupos AND Promoção à Saúde; Terceira idade AND Grupos AND Promoção a Saúde; Idoso AND Saúde; e Terceira idade AND Saúde.

Foram considerados os critérios de exclusão: monografias, dissertações, teses e revisões bibliográficas. Também foram excluídos os artigos que são relatos de experiências, mas não apresentaram avaliação; artigos que não descreveram claramente a intervenção; artigos que fizeram comparações entre pessoas participantes e não participantes dos grupos; artigos com práticas de promoção da saúde individual; artigos com foco nos trabalhos em grupos com as famílias cuidadoras e profissionais de saúde.

Após a aplicação dos critérios de inclusão e exclusão, iniciou-se o refinamento da busca por meio da leitura dos títulos e resumos dos artigos. Em seguida à fase de elegibilidade, os artigos foram incluídos. Na próxima etapa ocorreu a análise e categorização por meio da análise temática de Bardin (2002). Realizou-se a leitura do título dos artigos que foram incluídos nesta revisão sistemática, assim, verificou-se os aspectos em comum, após esta etapa ocorreu a construção das categorias temáticas.

\section{Resultados}

\footnotetext{
${ }^{1}$ É considerado como idoso pela Lei № 10.741 de 1ㅇ de Outubro de 2003 do Estatuto do Idoso (Brasil, 2003).
} 
A Figura 1 apresenta o fluxograma referente ao processo de busca e seleção dos artigos. Foram utilizados os critérios de inclusão e exclusão, e na fase de elegibilidade por meio da leitura do método foram incluídos quinze artigos artigos para a revisão sistemática.

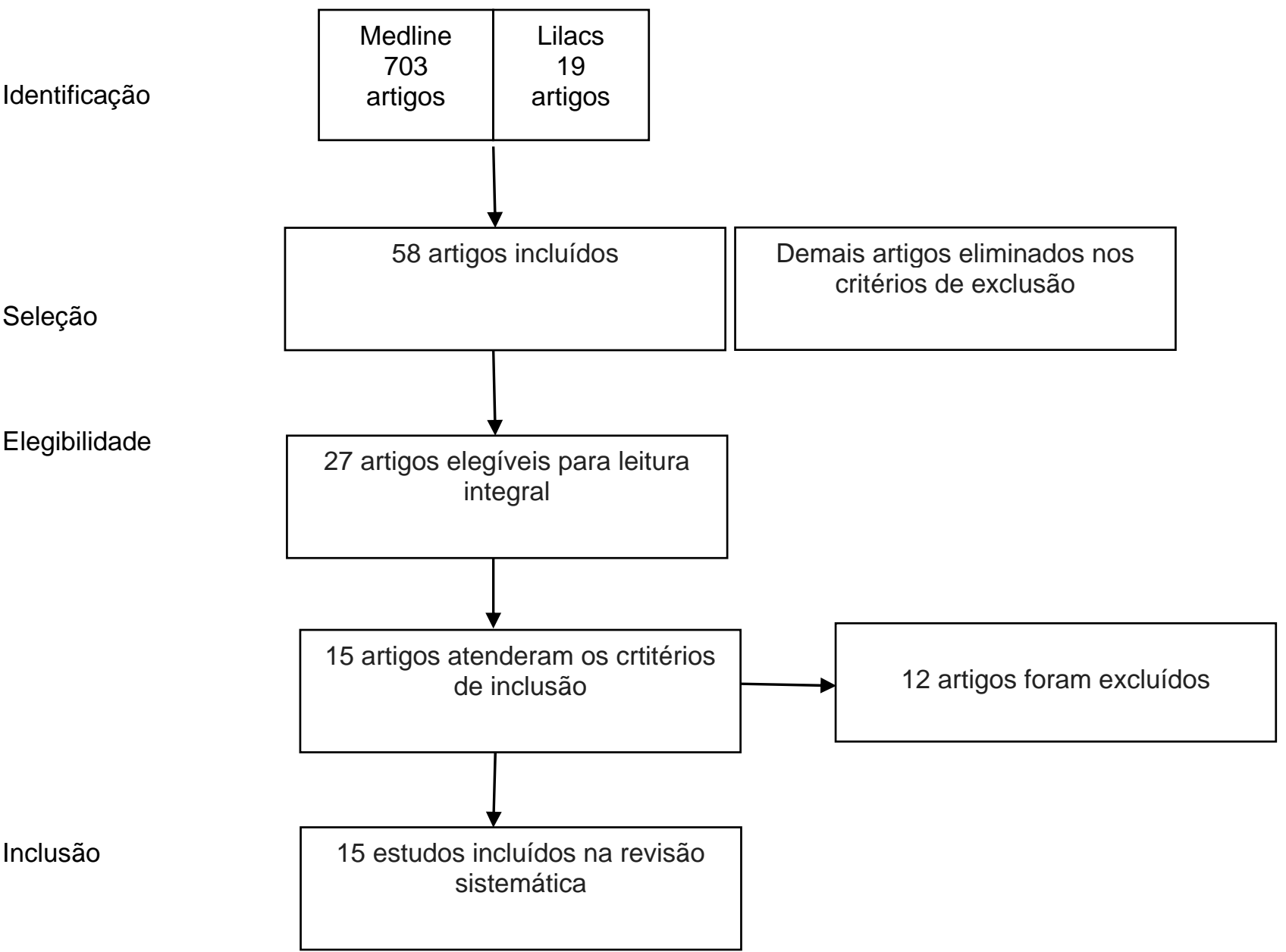

Figura 1. Fluxograma do processo de busca e seleção dos artigos.

Após as buscas dos artigos nas bases de dados e a utilização dos critérios de inclusão e exclusão, foram construídas as seguintes categorias temáticas: oficinas de educação em saúde, práticas recreativas, práticas corporais, e estimulação cognitiva.

A Tabela 1 apresenta o panorama das categorias temáticas e destacam-se os seguintes pontos: o maior número de mulheres participantes; os diferentes locais para o desenvolvimento dos grupos (unidades básicas de saúde, grupos de convivência, igreja, praça) e a vinvulação de projetos vinculados as universidades; a variedade de ações educativas realizadas de maneira integrada (atividade física e recreativa), e de maneira específica, por exemplo, atividade corporal, oficina de memória; e as distintas estratégias de avaliação com ênfase na avaliação em grupo. Dois estudos foram realizados por uma equipe multiprofissional numa perspectiva interdisciplinar. Foram identificados estudos realizados na comunidade 
e nos grupos de convivência, o que demonstra a intersetorialidade. Profissionais de diferentes áreas da saúde, da assistência social, e pessoas da comunidade foram coordenadores dos grupos de promoção da saúde.

Nove artigos foram incluídos na categoria oficinas de educação em saúde, e referem-se aos estudos que desenvolveram práticas de promoção da saúde por meio da integração de diversas temáticas, por exemplo, atividades de educação em saúde, de educação física, recreativa, e de socialização. Para a avaliação dos efeitos destas práticas, os pesquisadores utilizaram grupos focais, questionário estruturado e instrumentos de avaliação quantitativos. Dois estudos avaliaram os efeitos de práticas recreativas, o primeiro por meio de grupo focal e o segundo mediante entrevista individual. Dois estudos avaliaram ações de práticas corporais por meio do questionário SF-36 e grupo focal. E dois estudos avaliaram práticas referentes a estimulação cognitiva por meio de grupo focal e questionário estruturado. Assim, é possível ressaltar que para a avaliação das ações educativas, os estudos valorizam os relatos produzidos em grupo, se comparada a baixa utilização de instrumentos quantitativos. Por outro lado, qualidade de vida e estado geral de saúde são variáveis de interesse de pesquisadores na avaliação quantitativa.

Tabela 1. Categorias temáticas e artigos referentes a avaliação de grupos de promoção da saúde no envelhecimento.

Notas: $\mathrm{M}=$ Mulher/ $\mathrm{H}=\mathrm{Homem}$

\begin{tabular}{|c|c|c|c|c|c|}
\hline $\begin{array}{c}\text { Categorias } \\
\text { temáticas e } \\
\text { artigos incluídos }\end{array}$ & Autor/Ano & Gênero & $\begin{array}{l}\text { Local/ } \\
\text { Profissionais } \\
\text { envolvidos }\end{array}$ & Ações educativas & $\begin{array}{l}\text { Estratégia de } \\
\text { avaliação }\end{array}$ \\
\hline
\end{tabular}

\section{Oficinas de educação em saúde}

Projeto conviver: Andrade, estímulo à Mendonça, convivência Lima, Bonolo, entre idosos do e Fátima

Catete, Ouro (2012)

Preto, MG

A experiência de oficinas educativas com idosos: (re) pensando práticas à luz do pensamento freireano
Costa, Rabelo, M e Lima (2014)

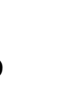

Comunidade/
Agentes
comunitários
de saúde
Envelhecimento saudável
Unidade de Sono, hipertensão
saúde da arterial,
família/ medicamentos,
Discentes e doenças reumáticas,
docentes de memória, e quedas
enfermagem

Grupo focal

(u)

Questionário

\section{Oficinas de educação em saúde}




\begin{tabular}{|c|c|c|c|c|c|}
\hline $\begin{array}{l}\text { Fatores } \\
\text { terapêuticos } \\
\text { identificados em } \\
\text { um grupo de } \\
\text { promoção da } \\
\text { saúde de idosos }\end{array}$ & $\begin{array}{l}\text { Nogueira, } \\
\text { Munari, } \\
\text { Santos, } \\
\text { Oliveira, e } \\
\text { Fortuna (2013) }\end{array}$ & - & $\begin{array}{ll}\text { Unidade } & \text { de } \\
\text { saúde } & \text { da } \\
\text { família/ } & \\
\text { Agentes } & \\
\text { comunitários } \\
\text { de saúde }\end{array}$ & $\begin{array}{lr}\text { Atividade } & \text { física, } \\
\text { recreativa } & \text { e } \\
\text { socialização } & \end{array}$ & Grupo focal \\
\hline $\begin{array}{l}\text { Efeitos de uma } \\
\text { intervenção } \\
\text { educativa sobre } \\
\text { a utilização de } \\
\text { serviços de } \\
\text { saúde por } \\
\text { homens idosos }\end{array}$ & $\begin{array}{l}\text { Borges e Seidl } \\
\text { (2013) }\end{array}$ & $13(H)$ & $\begin{array}{l}\text { Grupo de } \\
\text { convivência }\end{array}$ & geral & $\begin{array}{l}\text { Questionário } \\
\text { de Avaliação } \\
\text { da Saúde do } \\
\text { Homem Idoso } \\
\text { (QUASHI) }\end{array}$ \\
\hline $\begin{array}{l}\text { Contribuições } \\
\text { de um grupo da } \\
\text { terceira idade } \\
\text { para a saúde } \\
\text { das idosas } \\
\text { participantes }\end{array}$ & $\begin{array}{l}\text { Cavalcante, } \\
\text { Dantas, } \\
\text { Araújo, } \\
\text { Magalhães, e } \\
\text { Neves (2015) }\end{array}$ & $20(M)$ & $\begin{array}{l}\text { Centro de } \\
\text { Referência da } \\
\text { Assistência } \\
\text { social/ } \\
\text { Assistente } \\
\text { social, } \\
\text { psicóloga, } \\
\text { artesã, e } \\
\text { educador físico }\end{array}$ & $\begin{array}{lr}\text { Atividades } & \text { físicas, } \\
\text { recreativas } & \mathrm{e} \\
\text { ocupacionais } & \end{array}$ & $\begin{array}{l}\text { Questionário } \\
\text { fechado }\end{array}$ \\
\hline $\begin{array}{lr}\text { Grupo } & \text { de } \\
\text { convivência } & \\
\text { como suporte ao } \\
\text { idoso } & \text { na } \\
\text { melhoria } & \text { da } \\
\text { saúde } & \end{array}$ & $\begin{array}{l}\text { Wichmann, } \\
\text { Couto, Areosa, } \\
\text { e Montanés } \\
(2013)\end{array}$ & $\begin{array}{l}\text { Brasil: } \\
205(\mathrm{M}) \\
57(\mathrm{H}) \\
\text { Espanha: } \\
130(\mathrm{M}) \\
132(\mathrm{H})\end{array}$ & $\begin{array}{l}\text { Universidades } \\
\text { e grupos de } \\
\text { convivência }\end{array}$ & $\begin{array}{l}\text { Memória, } \\
\text { relaxamento, } \\
\text { culinária, ginástica, } \\
\text { seminários }\end{array}$ & $\begin{array}{l}\text { Questionário } \\
\text { fechado }\end{array}$ \\
\hline $\begin{array}{lr}\text { Percepção } & \text { de } \\
\text { idosos } & \text { sobre } \\
\text { grupo } & \text { de } \\
\text { convivência: } & \\
\text { estudo } & \text { na } \\
\text { cidade } & \text { de } \\
\text { Cajazeiras } & \end{array}$ & $\begin{array}{l}\text { Andrade et al. } \\
\text { (2014) }\end{array}$ & $\begin{array}{l}48(\mathrm{M}) \\
12(\mathrm{H})\end{array}$ & $\begin{array}{l}\text { Grupos de } \\
\text { convivência }\end{array}$ & $\begin{array}{l}\text { Dança, atividade } \\
\text { física, passeio, e } \\
\text { artesanato }\end{array}$ & $\begin{array}{l}\text { Questionário } \\
\text { fechado }\end{array}$ \\
\hline $\begin{array}{lr}\text { Qualidade de } \\
\text { vida e nível } \\
\text { cognitivo de } \\
\text { pessoas idosas } \\
\text { participantes de } \\
\text { grupos } & \text { de } \\
\text { convivência }\end{array}$ & $\begin{array}{l}\text { Leite, Winck, } \\
\text { Hildebrandt, } \\
\text { Kirchner, e } \\
\text { Silva (2012) }\end{array}$ & $\begin{array}{l}79(\mathrm{M}) \\
6(\mathrm{H})\end{array}$ & $\begin{array}{l}\text { Igreja - grupo } \\
\text { de } \\
\text { convivência/ } \\
\text { Profissional da } \\
\text { secretaria } \\
\text { municipal de } \\
\text { ação social }\end{array}$ & $\begin{array}{l}\text { Artesanato, dança, } \\
\text { passeios, exercícios } \\
\text { físicos e socialização }\end{array}$ & $\begin{array}{l}\text { Questionário } \\
\text { de estado de } \\
\text { saúde } \\
\text { Medical } \\
\text { Outcomes } \\
\text { Study } 36 \text { - Item } \\
\text { Short-Form } \\
\text { Health Survey - } \\
\text { SF-36 }\end{array}$ \\
\hline $\begin{array}{lr}\text { Qualidade } & \text { de } \\
\text { vida } & \text { para } \\
\text { avaliação } & \text { de } \\
\text { grupos } & \text { de } \\
\text { promoção } & \text { da } \\
\text { saúde } & \end{array}$ & $\begin{array}{l}\text { Paula et al. } \\
(2016)\end{array}$ & $\begin{array}{l}18(\mathrm{M}) \\
2(\mathrm{H})\end{array}$ & $\begin{array}{l}\text { Unidade } \\
\text { básica de } \\
\text { saúde e praça/ } \\
\text { Enfermagem, } \\
\text { educador físico } \\
\text { e comunidade }\end{array}$ & $\begin{array}{l}\text { Educação em saúde } \\
\text { e atividade física. }\end{array}$ & $\begin{array}{l}\text { Questionário } \\
\text { de qualidade } \\
\text { de vidal } \\
\text { Questionário } \\
\text { de qualidade } \\
\text { de vida do } \\
\text { idoso }\end{array}$ \\
\hline
\end{tabular}




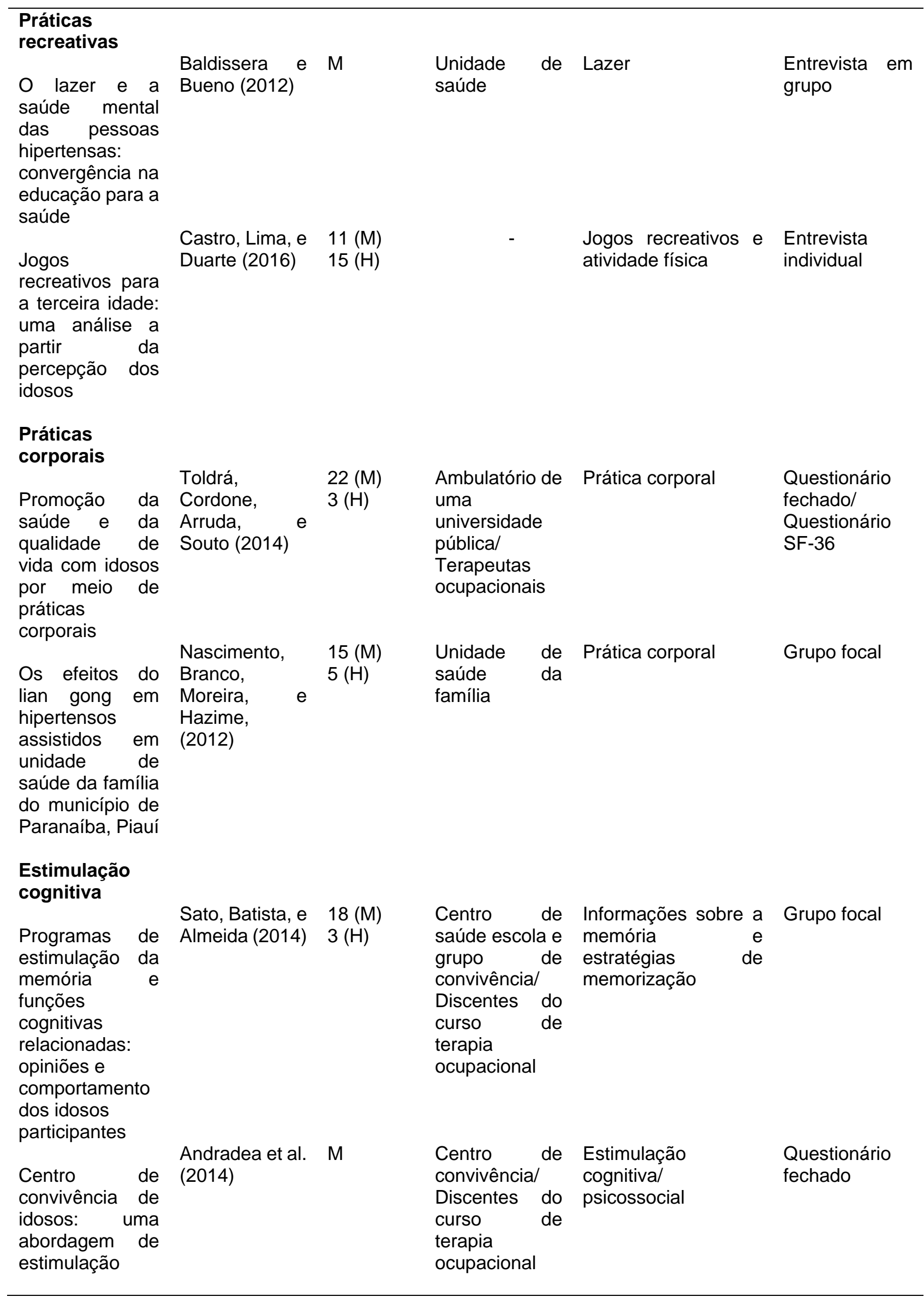


cognitiva e

psicossocial

O desenvolvimento do projeto conviver foi uma iniciativa de pesquisadores para a discussão de temáticas com os idosos em oito oficinas de grupos operativos, realizadas uma vez na semana (Andrade, Mendonça, Lima, Alfenas, \& Bonolo, 2012). Realizou-se uma oficina de atividade física, especificamente sobre os benefícios da caminhada, na qual foram apresentadas informações gerais desta atividade e as repercussões na qualidade de vida. Uma oficina de música e dança foi realizada para destacar as contribuições destas atividades para a memória e saúde integral. A terceira oficina foi sobre os jogos recreativos, por exemplo, baralho, dama, dominó, e os benefícios para o raciocínio e lazer. A quarta oficina foi destinada para a apresentação de informações sobre ansiedade e depressão, para que os mesmos pudessem compartilhar e esclarecer informações sobre estados emocionais. E outra oficina sobre alimentação saudável, na qual os monitores da pesquisa realizaram a montagem de uma mesa de café da manhã com alimentos saudáveis. No último encontro os participantes foram convidados para avaliar as oficinas. Os participantes mostraram-se satisfeitos com as oficinas pelo fato de que reconheceram a importância da convivência, do compartilhamento de experiências, da interação social e dos cuidados com a saúde integral, por exemplo, ocorreu a adesão aos estilos de vida saudáveis que promovem saúde.

Ações de promoção da saúde foram realizadas em um grupo de 15 idosos de uma unidade de saúde da família, o que integrou as seguintes temáticas em seis encontros: higiene do sono, informações sobre hipertensão arterial e diabetes, uso de medicamentos, doenças reumáticas, oficina de memória, e prevenção de quedas (Costa, Rabelo, \& Lima, 2014). Os participantes avaliaram os encontros por meio de um questionário estruturado entre muito ruim e muito bom. $E$ também foi analisado o nível de conhecimento das temáticas antes e depois das intervenções. Inicialmente foram realizadas rodas de conversas para discutir a temática do envelhecimento e higiene do sono, em seguida foram apresentadas informações básicas sobre a hipertensão e diabetes. No que se refere a temática uso de medicamentos, os mediadores do grupo representados por profissionais de diferentes áreas da saúde, realizaram uma dramatização por meio de uma peça teatral e em seguida ocorreu uma discussão. Realizou-se uma palestra sobre as doenças reumáticas com informações gerais referentes aos sintomas, comprometimentos e medicação. E para discutir a prevenção de quedas foi realizada uma oficina, na qual os participantes eram solicitados para identificar os objetos que estavam dentro de um saco, e posteriormente foram apresentados os medicamentos utilizados para a memória. Os participantes consideraram muito satisfatórios os conteúdos e a metodologia das atividades. O conhecimento das temáticas antes das intervenções foi classificado em regular, e após as intervenções foi considerado muito satisfatório. Isto indica a importância de avaliar as fases pré e pós intervenção, o que possibilita selecionar as atividades para novas aplicações e identificar as contribuições das práticas de promoção da saúde. 
Pesquisadores realizaram um estudo com o objetivo de identificar os fatores terapêuticos provenientes da participação de 23 idosos nas atividades físicas, recreativas e de socialização, realizadas semanalmente em uma unidade básica de saúde com a duração de noventa minutos (Nogueira, Munari, Santos, Oliveira, \& Fortuna, 2013). Utilizou-se o grupo focal para explorar as motivações do grupo para a realização das atividades, as repercussões na vida e os aspectos da manutenção do grupo. Foram identificados oito fatores terapêuticos: coesão trata-se da interação entre os membros do grupo e da valorização do vínculo social; esperança - desenvolvimento de novas formas de enfrentamento de problemas provenientes da participação no grupo, por exemplo, manejo do estresse; socialização - o compartilhamento de experiências e de habilidades sociais, por exemplo, brincar, sorrir, cantar; compartilhamento de informações - a maneira pela qual as informações adquiridas são compartilhadas entre os membros do grupo, por exemplo, a atividade física; fatores existenciais - vivências que permitem desenvolver reflexões sobre aspectos da vida humana, por exemplo, a convivência e a tolerância nas relações sociais; altruísmo - ajuda mútua entre os integrantes e a satisfação; aprendizagem interpessoal - aprendizagens que ocorreram nas interações sociais, por exemplo, realizar atividades com dedicação e valorizar momentos felizes; e universalidade - momento que os integrantes compartilhavam e discutiam experiências de vida, o que permitiu desenvolver a empatia. É importante ressaltar que os fatores terapêuticos decorrentes de práticas de promoção da saúde viabilizam a construção de novas estratégias de intervenção, e indicam a necessidade de considerar as ações educativas e terapêuticas para a saúde integral.

Uma intervenção educativa foi aplicada em 13 homens que frequentavam um grupo de convivência para idosos (Borges \& Seidl, 2013). Foram realizadas nove sessões, periodicidade semanal e a duração foi de aproximadamente 90 minutos para cada sessão, com as seguintes temáticas referentes a saúde do homem: limites e potencialidades do envelhecimento, aspectos da saúde do homem, e prevenção de câncer de próstata. No que se refere as estratégias de intervenção: materiais educativos (escritos/vídeo), dinâmicas de grupo, dramatizações e discussões. Após as intervenções foram realizados dois encontros para avaliações individuais por meio do Questionário de Avaliação da Saúde do Homem Idoso (QUASHI), o objetivo foi verificar as mudanças comportamentais dos participantes. Uma semana após a intervenção foram realizadas entrevistas, e após quatro meses a entrevista foi realizada novamente. Antes da intervenção, verificou-se que os idosos realizaram 52 consultas médicas nos últimos doze meses, aproximadamente quatro consultas por mês. Após a intervenção, verificou-se aumento no número de consultas, média de seis consultas por mês. Entre a segunda e terceira avaliações, a média de consultas foi de 4,75, e no intervalo de tempo total nas avaliações referente a 19 meses, identificou-se uma média de 6,8 consultas por participante. Na fase pósintervenção, identificou-se aumento no número de visitas médicas em dez participantes. Destaca-se que a adesão do homem aos serviços de saúde representa um desafio, mas por outro lado quando são realizadas ações 
educativas é possível verificar os novos hábitos e as mudanças comportamentais, o que representa um ponto positivo para o cuidado com a saúde e a prevenção de doenças. Desta forma, a realização destas ações na comunidade representa uma oportunidade para fomentar a saúde coletiva.

Pesquisadores avaliaram os efeitos de atividades físicas, recreativas e ocupacionais desenvolvidas por 20 idosas que frequentavam um grupo de convivência, duas vezes por semana, regularmente no período de um ano (Cavalcante, Dantas, Araújo, Magalhães, \& Neves, 2015). Utilizou-se um questionário fechado para verificar as percepções dos idosos sobre a participação nos grupos. Verificou-se que após a participação nestas atividades, os idosos estavam praticando atividades de flexibilidade referentes a levantar, sentar, curvar e dobrar, e 55\% consideraram o estado de saúde bom. A inserção nas atividades foi motivada pelo interesse de desenvolver amizades e para auxiliar nos cuidados com a saúde. Entre as atividades desenvolvidas, a prática de atividade física foi considerada a preferida, e após a participação no grupo se sentiram satisfeitos com a vida e valorizados socialmente. No que se refere as contribuições do grupo, foram identificados relatos de disposição e resistência para a prática de atividades físicas, a convivência social e a expressão das emoções.

Outros autores buscaram investigar as percepções de 262 idosos brasileiros e 262 espanhóis referentes a participação nos grupos de convivência (Wichmann, Couto, Areosa, \& Montanés, 2013). Os idosos participaram de grupos de autocuidado e de atividades físicas que focalizavam hábitos saudáveis, por exemplo, oficinas de relaxamento, de memória, de culinária, de ginástica. Os participantes relataram que a participação nos grupos representou uma possibilidade para a criação de amizades, o compartilhamento de emoções, e melhores condições de saúde, estes que representam os motivos para a inserção no grupo e que apresentam benefícios para a saúde integral. Por exemplo, foram apresentados relatos sobre melhorias na capacidade funcional referentes a memória e ao manejo da pressão arterial. Socialização, melhora da saúde física e mental, e a ampliação de conhecimentos representaram os principais temas identificados nas duas amostras, especificamente os brasileiros se referiram as condições de saúde e socialização, e os espanhóis identificaram os benefícios referentes a socialização e condições de saúde. Por outro lado, verificou-se que os grupos de convivência representam redes de suporte social e de fortalecimento de vínculos.

As percepções de 60 idosos em grupos de convivência foram analisadas por meio de um questionário estruturado (Andrade et al., 2014). Verificou-se que 23 participantes frequentavam os grupos entre 6-10 anos, e a maioria $(n=33)$ não tinha apoio da família, assim a inserção no grupo ocorreu de maneira espontânea. Foram identificadas as principais atividades desenvolvidas no grupo: dança, educação física, passeio e artesanato. Para os participantes, a convivência nos grupos possibilita minimizar a solidão e permite vivenciar experiências recreativas. Além disso, reconheceram a importância dos grupos para a construção de vínculos sociais de amizades, o que representa um elemento facilitador para expressar ideias, em síntese, a liberdade de expressão. No que se refere as mudanças 
provenientes da participação nos grupos, verificou-se melhorias na disposição para as práticas de atividades físicas, e melhorias nos estados de humor pelo fato de que identificaram sentimentos de alegria. Outro ponto se refere a atribuição de novos sentidos para a vida devido a percepção de saudável e feliz, pois tiveram a oportunidade de conhecer espaços sociais para o desenvolvimento de interações. É possível verificar aspectos da promoção da saúde nos relatos dos participantes desta pesquisa, por exemplo, a interação social e os benefícios para a qualidade de vida.

Um estudo buscou avaliar a qualidade de vida de 85 idosos participantes de grupos de convivência (Leite, Winck, Hildebrandt, Kirchner, \& Silva, 2012). Neste grupo os idosos realizavam as atividades de artesanato, dança, passeios, exercícios físicos e socialização, com periodicidade semanal, coordenado por um profissional da secretaria municipal de ação social. Foram utilizados o mini=exame do estado mental para avaliação de funções cognitivas, e o questionário de estado de saúde- Medical Outcomes Study 36 - Item Short-Form Health Survey- SF-36. Identificou-se declínio cognitivo ( $n=20)$, a média de pontuação foi de 25,99 numa escala de 16 a 30. No questionário SF-36, as maiores médias foram identificadas nas facetas: saúde mental, estado geral de saúde, vitalidade, e aspectos sociais. Neste estudo, a identificação de pessoas com declínios cognitivos possibilita o desenvolvimento de novas atividades para evitar o agravamento de sintomas, um aspecto importante para considerar as necessidades deste grupo. Por outro lado, os resultados do SF-36 indicam a satisfação com a saúde, assim, a manutenção deste grupo apresenta benefícios para a promoção da saúde.

A avaliação da qualidade de vida foi realizada após a participação de 46 idosos em grupos de promoção da saúde na comunidade (Paula et al., 2016). O estudo foi realizado em duas unidades básicas de saúde, especificamente com dois grupos. O primeiro grupo participava de atividades de aferição da pressão arterial, alongamento, recreação, e palestras de educação em saúde. O segundo grupo participava de atividades numa praça pública, três vezes na semana, o que incluía caminhada, dança, atividade física, educação em saúde, verificação de pressão arterial e teste glicêmico. Estes dois grupos eram coordenados por pessoas da comunidade e profissionais da saúde.

Os participantes preencheram o questionário de qualidade de vida, e questionário de qualidade de vida do idoso. No primeiro grupo a maior média foi identificada no domínio referente as relações sociais, e a menor média no domínio meio ambiente. No segundo grupo a maior média foi no domínio psicológico, e a menor média no domínio meio ambiente. Verificou-se diferença estatisticamente significativa nos escores do domínio relações sociais com a maior média para o primeiro grupo. No questionário de qualidade de vida do idoso, o primeiro grupo apresentou maior escore na faceta participação social, e o segundo grupo atingiu maior escore na faceta atividades passadas, presentes e futuras. A menor média nos dois grupos foi identificada na faceta morte e morrer. Em síntese, existem relações nos resultados dos instrumentos que foram utilizados, as relações sociais e a participação social representam indicadores de qualidade de vida, e que foram provenientes das ações de promoção da saúde. 


\section{Práticas recreativas}

Seis participantes de um grupo de reunião semanal participaram de quatro encontros de intervenção educativa em saúde sobre o lazer (Baldissera \& Bueno, 2012). No primeiro momento foi realizado grupo focal e foi discutida a temática lazer, duplas colocaram tarjetas no mural, o que possibilitou a exposição de ideias e reflexões. Em seguida, foi realizada dinâmica de grupo referente ao enfrentamento das adversidades da vida, o manejo da hipertensão arterial, e informações sobre a utilização do lazer. Os pesquisadores apresentaram frases numa folha e os participantes compartilhavam suas opiniões, posteriormente foi realizada a oficina de bingo para os participantes vivenciarem o lazer. No último encontro realizou-se a avaliação por meio de entrevista em grupo para verificar os relatos dos participantes sobre a ocorrência de mudanças provenientes do tema lazer. De acordo com os autores, os participantes demonstraram satisfação nas etapas de intervenção, pois perceberam a necessidade do lazer na vida pelo fato de que os encontros foram geradores de alegria, de distração, de convivência, e de contribuições para a saúde.

Uma pesquisa buscou avaliar as percepções de idosos sobre a participação, ao longo do ano, em atividades de jogos recreativos e atividades físicas, e àqueles inscritos num evento de jogos recreativos da terceira idade (Castro, Lima, \& Duarte, 2016). Um participante de cada modalidade (buraco, bisca, truco, dama, xadrez, tênis de mesa, dança de salão, lancebol, voleibol adaptado, boliche adaptado, natação, corrida de 3.000 metros e sinuca) foi selecionado para participar da pesquisa. Nas entrevistas verificou-se que a participação nos jogos recreativos promoveu a interação social por meio de amizades e novos contatos, o que gerou convivência e qualidade de vida. Outro aspecto se referiu aos cuidados com a saúde, pelo fato de que os participantes relataram as contribuições das atividades recreativas para a saúde integral, o que inclui o bem-estar e a disposição física. Segundo os participantes, os jogos recreativos representaram atividades motivacionais para um estilo de vida saudável, o que permitiu desenvolver a conscientização da importância de manter o corpo em movimento e da manutenção nas atividades físicas e recreativas.

É possível apresentar a hipótese de que o lazer representa uma estratégia motivacional para a inclusão social de idosos, e neste sentido, o oferecimento de práticas recreativas na comunidade e nos serviços básicos de saúde possibilita auxiliar a participação social e desenvolver a satisfação com a vida.

\section{Práticas corporais}

Pesquisadores realizaram a aplicação de práticas corporais por meio do método self-healing, este que integra movimento, respiração, e automassagem, numa amostra de 25 pessoas em doze encontros, aproximadamente com meia hora de duração (Toldrá, Cordone, Arruda, \& Souto, 2014). Foram utilizados instrumentos de avaliação no primeiro e último encontro (Questionário SF-36 - 
Medical Outcomes Study 36 - Item Short-Form Health Survey, e questionário semiestruturado). Na avaliação inicial utilizou-se um questionário, e após a intervenção verificava-se a frequência e as dificuldades para aplicar as orientações, e as mudanças corporais na realização das atividades cotidianas.

No início da sessão os participantes relatavam sobre as práticas corporais realizadas em casa, apresentavam discussões sobre as rotinas e esclareciam dúvidas. No final da sessão buscou-se identificar as percepções sobre os efeitos das atividades desenvolvidas e o compartilhamento de experiências. $\mathrm{Na}$ avaliação final verificou-se que as orientações compartilhadas no grupo eram realizadas em casa, uma ou várias vezes ao dia, por exemplo, os movimentos na posição deitada, sentada, em pé, técnicas de respiração e automassagem. Todos os participantes relataram melhorias na realização dos movimentos, especificamente no alívio da dor e desconforto $(n=19)$, disposição física $(n=22)$ e mental $(n=23)$, no estado emocional $(n=17)$ e nos cuidados com o corpo $(n=19)$. E no que se refere aos efeitos das práticas corporais nas atividades cotidianas, 16 participantes perceberam melhorias, o que ocorreu na disposição, nas capacidades e ajustes corporais, e na redução da dor. Verificou-se que 9 participantes não relataram as repercussões provenientes das práticas corporais. Por outro lado, após a intervenção ocorreram melhorias nos seguintes domínios do SF-36: aspectos físicos, emocionais e dor.

Em outro estudo pesquisadores verificaram os efeitos de uma prática corporal em 20 hipertensos, realizada em 30 sessões, três vezes por semana em dias alternados, e para avaliação utilizou-se a técnica de grupo focal antes e depois da intervenção (Nascimento, Branco, Moreira, \& Hazime, 2012). Utilizou-se a técnica de Lian Gong caracterizada pelos movimentos sincronizados que associa música lenta com a respiração. Antes da intervenção os participantes apresentaram as percepções da doença referentes aos sintomas físicos, as alterações emocionais de ansiedade e depressão, as limitações na alimentação, as dificuldades na adesão ao tratamento, e a automedicação. Isto indicou a falta de conhecimento sobre a hipertensão e as dificuldades para o enfrentamento das repercussões vivenciadas. Após a intervenção, verificou-se nos relatos dos participantes, melhorias dos sinais e sintomas da hipertensão, principalmente no alívio da dor. Ocorreram melhorias no sono e nos sintomas de ansiedade e depressão, o que gerou interação social com os familiares. Outro aspecto se referiu a adesão ao tratamento por meio de acesso aos serviços de saúde para avaliações com profissionais de saúde, o que ocorreu também com a inclusão das práticas corporais. As mudanças nos hábitos alimentares por meio de dieta específica foram realizadas pelos participantes.

Diante destes estudos de práticas corporais, é possível compreender que as atividades relacionadas ao corpo estimulam o indivíduo para o desenvolvimento da consciência corporal, isto apresentou repercussões no alívio da dor, promoveu mudanças emocionais, e adesão ao tratamento. Estas práticas corporais são importantes para manter o corpo em movimento e promover qualidade de vida.

\section{Estimulação cognitiva}


Um estudo desenvolveu e avaliou um Programa de Estimulação da Memória (PEM) em 21 idosos, dez encontros semanais de duas horas (Sato, Batista, \& Almeida, 2014). Este programa apresentava uma proposta educativa e durante os encontros eram apresentadas as definições de memória e seu funcionamento, as relações entre memórias e estilos de vida, e estratégias para melhorias da memória e suas funções relacionadas. Os participantes eram entrevistados por meio de grupos focais antes e depois dos dez encontros. Quatro grupos focais foram realizados, e em cada grupo tinha entre 5 a 6 participantes, assim buscava-se identificar as repercussões do PEM na vida cotidiana, e a avaliação sobre a participação no PEM.

Antes das intervenções foram identificados os relatos de dificuldades cognitivas referentes aos esquecimentos de palavras e ações. Os participantes relataram que o PEM possibilitou motivá-los para o desenvolvimento das seguintes atividades: leituras, jogos, costura, viagens, preparo de alimentação, e utilização de meios de transporte. No que se refere as estratégias para auxiliar o desempenho da memória, verificou-se a utilização de dispositivos externos para anotações de compromissos, lembretes, lista de compras, para gerenciar o uso de medicamentos, escrever situações do cotidiano, e utilizar o despertador. Estratégias de atenção, associação e repetição também foram utilizadas para lembrar de nomes, números, e de compromissos. O PEM possibilitou desenvolver a reflexão nos participantes sobre estilos de vida saudáveis, o que ocorreu por meio da autopercepção da memória e as repercussões na redução da ansiedade, assim como, no desenvolvimento de atividades domésticas, nos compromissos, na comunicação, e na orientação espacial referente a memorizar roteiros. Neste sentido, os participantes destacaram as contribuições do PEM, pelo fato de que permitiu desenvolver aprendizados, utilizar estratégias, e construir vínculos sociais. Por outro lado, sugeriram a continuidade do PEM com outros módulos, a reformulação dos módulos com uma linguagem acessível, a ampliação do número de encontros, a utilização de exercícios práticos e de tarefas de casa focalizados nas necessidades de cada pessoa.

Em outro estudo procurou-se desenvolver uma oficina de estimulação cognitiva e psicossocial em um centro de convivência, com 13 encontros de aproximadamente uma hora de duração, periodicidade semanal, em média com oito participantes em cada encontro (Andradea et al., 2014). Foram realizadas dinâmicas de grupo sobre temáticas diversas, por exemplo, a dinâmica da música, na qual músicas eram apresentadas e os participantes estimulados a identificar o nome da música, o cantor, e a continuar cantando. Dinâmica das celebridades por meio da apresentação de imagens de artistas, assim os participantes eram convidados para dizer o nome e a trajetória do artista. Uma atividade foi proposta para estimular a memória sensorial (tato e olfato), alguns alimentos foram selecionados e oferecidos para os participantes com os olhos vendados. Outra dinâmica foi sobre o caminho de casa, na qual os participantes escreveram o caminho percorrido de sua casa até o centro de convivência. Atividades desenvolvidas de maneira interativa referentes aos jogos recreativos e de 
memória, por exemplo, dominó, dama, palavras cruzadas, e jogos com palavras para serem representados por meio de mímicas. Em cada encontro os participantes avaliaram as atividades desenvolvidas nas oficinas por meio de questionário estruturado, assim verificou-se a satisfação de todos, principalmente no jogo de celebridades, e nos jogos de estimulação da memória. Isto permitiu aos pesquisadores identificar as atividades que receberam a classificação excelente, e assim selecioná-las para os próximos grupos.

Nestes dois estudos sobre estimulação cognitiva, as avaliações antes e depois da intervenção indicam mudanças significativas, o que mostra a importância de desenvolver atividades referentes as funções cognitivas, principalmente por meio de atividades interativas que valorizam as vivências cotidianas.

\section{Discussão}

Uma revisão de literatura referente a programas de promoção da saúde para idosos indicou que a maior participação nos programas é de mulheres (Assis, et al., 2004), o que apresenta congruência com os resultados identificados nesta revisão sistemática. De acordo com Goldenberg (2014), as mulheres se sentem livres na velhice por não terem a responsabilidade de cuidar de filhos e maridos, assim existe disponibilidade de tempo para o autocuidado, por outro lado, os homens nesta fase estão cansados do trabalho e preferem o ambiente familiar.

Nesse sentido, Carmagnanis (2016) apresentou reflexões referentes às representações sociais femininas e masculinas na sociedade. $\mathrm{O}$ autor considera que as mulheres utilizam a liberdade para cuidar de si mesmas mediante a busca de atividades para preencher o tempo livre, enquanto os homens se dedicam aos assuntos financeiros do ambiente familiar. Os pesquisadores têm o interesse de compreender a participação minoritária masculina nos programas de saúde, pois os homens se mostram interessados em participarde discussões sobre assuntos econômicos e politicos (Debert, 2012). Para a autora, essa diferença está fundamentadanosestigmas compartilhados no meio cultural referentes aohomem trabalhador e a mulher dona-de-casa.

As ações educativas em grupo apresentadas nesta revisão sistemática, por exemplo, jogos recreativos, atividade física, atividade recreativa, atividade ocupacional, focalizaram o princípio da integralidade ao considerar que a saúde é produzida na interação social. A imersão em um ambiente que favorece a troca de saberes, experiências, amizades e fortalecimento de laços sociais apresenta benefícios para fomentar o protagonismo e a participação social, o que representam princípios da política nacional da promoção da saúde (Brasil, 2014). $\mathrm{Na}$ literatura científica, os autores destacaram a importância da realização de trabalhos em grupo para promover a conscientização social, a participação e o desenvolvimento da autonomia das pessoas (Góis, 2008; Lane, 2001; Martin-Baró, 1989). Isto foi possível verificar nos estudos analisados nesta revisão sistemática, pois os participantes desenvolveram novos hábitos de vida e promoveram o autocuidado com a saúde, assim é possível inferir que as intervenções foram geradoras de promoção da saúde. O desenvolvimento de novas atitudes e as 
melhorias nas condições de vida e saúde das pessoas representam os benefícios provenientes da participação em grupos de promoção da saúde (Santos et al., 2006).

E referente as estratégias de avaliação das ações educativas, verificou-se a concentração de estudos na avaliação em grupo por meio dos relatos dos participantes. Assim, a análise qualitativa estava presente nestes estudos, o que permite destacar o interesse de pesquisadores de compreender a avaliação dos participantes. Entretando, em alguns estudos foram utilizados instrumentos de estado geral de saúde e qualidade de vida. Desta maneira, verifica-se uma associação entre ações de promoção da saúde, qualidade de vida e saúde geral. Independente do tipo de avaliação realizada, os estudos analisados nesta revisão sistemática atendem os princípios de práticas baseadas em evidências. Monteleone e Witter (2017) recomendam a utilização de avaliações sistemáticas para que os resultados permitam o aprimoramento de novas ações, pelo fato de que há uma escassez de práticas baseadas em evidências nos estudos com idosos.

Tais afirmações foram confirmadas nesta revisão sistemática, pois a análise incluiu quinze artigos produzidos no contexto brasileiro, um número considerado pequeno. É possível apresentar a hipótese de que os profissionais da saúde apresentam dedicação para o desenvolvimento de ações educativas de promoção da saúde no envelhecimento, mas poucos avaliam os resultados. Os relatos de experiência são importantes meios para estruturar propostas de atuação, mas a avaliação representa um elemento central para verificar os efeitos de intervenções. Assim, recomenda-se para os interessados nesta área, o desenvolvimento de habilidades para elaborar e avaliar programas de promoção da saúde, isto poderá ocorrer por meio da participação em cursos de extensão. É importante destacar que os artigos analisados nesta revisão focalizaram a dimensão dos resultados, por outro lado, autores recomendam avaliar o planejamento das intervenções, o contexto, e o processo de execução (Donabedian, 1984, 1987; Oliveira et al., 2017).

Um ponto para análise se refere a intersetorialidade e interdisciplinaridade nas ações de promoção da saúde no envelhecimento. Existe a necessidade do desenvolvimento de trabalhos intersetoriais e interdisciplinares por meio da participação do sujeito na sociedade, em consonância com a Política Nacional da Saúde da Pessoa Idosa que recomenda o trabalho conjunto da área de saúde em lugares de fácil acesso e baixo custo para contribuir com a participação social (Brasil, 2006). Por outro lado, existem desafios para a compreensão e operacionalização da intersetorialidade nas ações de promoção da saúde para idosos (Oliveira, Mattioli, Barcelos, Horta, \& Lacerda, 2017). Diante disto, é necessário promover cursos de extensão para os profissionais de saúde desenvolverem habilidades teóricas e práticas com o objetivo de utilizar diferentes contextos sociais para as ações de promoção da saúde.

Silva e Elali (2015) sugerem a realização de trabalhos em espaços abertos urbanos públicos para desenvolver jogos, teatros, encontros e espaços reflexivos. Atividades em unidades básicas de saúde também representam locais propícios 
para o desenvolvimento de grupos de promoção da saúde, pelo fato de estarem perto da comunidade e envolverem um grupo de profissionais de saúde.Um ponto positivo nesta revisão sistemática foi a identificação de estudosrealizados em espaços públicos, por exemplo, praça e igreja, por considerar que isto possibilita desenvolver pertencimento social as pessoas da comunidade, além disso, são ações congruentes com as propostas de saúde comunitária.Nas oficinas de educação em saúde os pesquisadores utilizaram os participantes que frequentavam grupos de convivência, o que viabiliza o desenvolvimento de estudos pelo fato de que existe um grupo com vínculo social. Fomentar ações de promoção da saúde na comunidade representa uma iniciativa que valoriza o contexto social e as pessoas envolvidas, especificamente para o idoso apresenta benefícios para a socialização e fortalecimento comunitário.

Nesta revisão sistemática foram identificados estudos vinculados às universidades referentes a projetos de extensão, o que representa uma estratégia que possibilita aos alunos relacionar aspectos teóricos e práticos articulados com a pesquisa. Destaca-se que estes projetos de extensão são realizados por meio de métodos específicos e orientados por professores pesquisadores, o que permite a operacionalização de etapas de pesquisa. Segundo Oliveira, Scortegagna e Oliveira (2015), os projetos de extensão com propostas de educação para os idosos favorecem a integração com a comunidade, e por outro lado, auxiliam possibilidades de pesquisas que buscam encontrar meios para que os idosos possam vivenciar melhorias na qualidade de vida. Articular a pesquisa no processo de intervenção representa algo relevante para apresentação de evidências científicas, mas para que isso ocorra é necessário a apropriação de conhecimentos de métodos de pesquisa, espeficamente as metodologias participativas para a intervenção com grupos.

Esta revisão sistemática identificou que os estudos sobre avaliação de programas de promoção da saúde no envelhecimento estão concentrados em categorias específicas: oficinas de educação em saúde, práticas recreativas, práticas corporais, e estimulação cognitiva. No que se refere a categoria oficinas educativas, foi possível verificar o desenvolvimento de intervenções por meio da integração de diferentes temas, por exemplo, educação em saúde para o desenvolvimento de estilo de vida saudável, autocuidado, atividade física e recreativa. Os resultados indicaram mudanças nos hábitos de vida dos participantes após a participação nas intervenções, especificamente nos cuidados com a saúde, por exemplo, alimentação saudável e aplicação dos conhecimentos adquiridos na vida cotidiana, aspectos que apresentaram repercussões nos estados emocionais, na qualidade de vida e na interação social. É possível destacar que a realização de oficinas de educação em saúde por meio da integração de atividades diversas representa uma estratégia que viabiliza a promoção da saúde e desenvolve no indivíduo a noção de responsabilidade com a saúde, o que provavelmente apresenta efeitos no autocuidado, aspecto central que previne doenças, aumenta a expectativa de vida e a satisfação nas suas atividades. 
A educação em saúde refere-se a um processo educativo no qual são construídos conhecimentos em saúde a serem apropriados pela população, ao considerar que as práticas educativas contribuem para fomentar a autonomia das pessoas sobre o autocuidado (Brasil, 2012). Isto foi possível verificar nos relatos dos participantes dos grupos de promoção da saúde, portanto, a apropriação de conhecimentos em saúde foi geradora de autonomia e autocuidado, aspectos congruentes com os princípios teóricos do Ministério da Saúde.

De acordo com Janini, Bessler, e Vargas (2015), a educação em saúde representa uma estratégia que promove saúde e permite fomentar a emancipação das pessoas. Estes autores realizaram um estudo numa unidade básica de saúde para verificar de que maneira as práticas educativas eram percebidas pelos idosos, o que foi possível identificar que os participantes valorizavam atividades em grupo sobre alimentação saudável, atividade física e controle de tabagismo, pelo fato de que conseguiram esclarecer informações e identificar fatores de risco, embora não tenha ocorrido uma avaliação para verificar de que forma os conhecimentos obtidos eram aplicados. Nesta revisão sistemática, os estudos incluídos na categoria oficinas de educação em saúde analisaram os impactos das informações obtidas pelos participantes, pois este ponto é fundamental para avaliar os efeitos de intervenções.

Um artigo na categoria oficinas educativas se referiu a saúde do homem por meio de práticas educativas que promoveram mudanças comportamentais, especificamente no aumentono número de consultas com profissionais de saúde. Em outro estudo, pesquisadores verificaram que os homens reconhecem a importância de hábitos saudáveis para a manutenção da saúde, mas apresentam resistência para seguir as orientações médicas (Trilico, Oliveira, Kijimura, \& Pirolo, 2015). Desta forma, é importante desenvolver ações de promoção da saúde para o homem, pois será possível fomentar a conscientizaçãoacerca de hábitos de vida para promover adesão aos tratamentos. Ao considerar os desafios para a inserção do homem nas práticas de promoção de saúde, recomenda-se um trabalho participativo entre comunidade e equipes de saúde da família. Além disso, campanhas publicitárias referentes a saúde do homem podem promover impactos positivos para envolver homens nos cuidados com a saúde.

Nas oficinas de educação em saúde foram desenvolvidas atividades físicas que promoveram disposição e satisfação nos participantes. Bottcher (2019) descreveu que as atividades físicas representam estratégias de promoção da saúde geradoras de benefícios para a saúde integral do indivíduo, o que possibilita também a prevenção de doenças. Os estudos sobre atividades físicas para idosos têm demonstrado as percepções dos participantes referentes a socialização e melhorias na disposição física (Moreno \& Tsukamoto, 2018; Yabuuti et al., 2019), o que apresenta congruência com os resultados dos estudos desta revisão sistemática. Outro estudo realizado em Taiwan desenvolveu um programa de educação em saúde para idosos em cinco comunidades, verificou-se na fase préintervenção que os participantes apresentavam obesidade, e desta forma, ocorreu o planejamento da ação educativa. Na comparação pré e pós-teste a percepção de saúde, de atividade física e de autocuidado indicou resultados positivos, e 
também foi destacada a satisfação geral dos participantes (Chang et al., 2017). Desta maneira, estes autores ressaltaram a importância de planejar e avaliar programas de promoção da saúde para idosos nas comunidades.

Ribeiro e Faustino (2013) realizaram uma revisão integrativa para verificar as ações de promoção da saúde para idosos. Foram identificados os seguintes temas: educação em saúde, envelhecimento saudável, saúde bucal, atividades físicas e recreativas. Os autores identificaram que as intervenções em grupo representam estratégias fundamentais para desenvolver discussões, promover mudanças comportamentais e auxiliar a interação social demaneira dinâmica.Outra revisão integrativa identificou as intervenções educativas realizadas pelos enfermeiros para idosos: orientações educativas durante as consultas, acompanhamento domiciliar, dinâmicas motivacionais, e sessões educativas com a utilização do lúdico (Carvalho et al., 2018). Percebe-se que a área da enfermagem se dedica as intervenções de promoção da saúde. A presença de diferentes profissionais de saúde e áreas distintas nas ações de promoção da saúde no envelhecimento contribui para efetivar a interdisciplinaridade. Em dois estudos nesta revisão sistemática foi identificada a interdisciplinaridade, e desta forma, independente da área de atuação, os profissionais tem a responsabilidade de efetivar os princípios das políticas públicas na realização de suas práticas. Ações de promoção da saúde de uma área específica apresentam resultados positivos, conforme foram destacados nos resultados, mas a ampliação das práticas por meio da participação de outros profissionais apresenta maiores benefícios para todos os envolvidos, por considerar a articulação dos diferentes conhecimentos.

E sobre as práticas recreativas, os estudos desta revisão sistemática mostraram os efeitos positivos das atividades de lazer na socialização, na construção de identidade grupal e nos vínculos sociais. Isto apresenta congruência com os princípios e diretrizes da política nacional da promoção da saúde (Brasil, 2014). É possível apresentar a hipótese de que o lazer representa uma estratégia motivacional que permite integrar os idosos, por exemplo, a utilização da música, do teatro e dos jogos recreativos possibilita a construção de um ambiente saudável para a socialização. Estratégias dinâmicas permitem aos idosos a aquisição de conhecimentos, inicialmente motivados pela via da emoção, em virtude da satisfação e das mudanças emocionais. Posteriormente será viável a aplicação destes conhecimentos nas atividades cotidianas, pelo fato de que foi atribuído um sentido a participação nas intervenções.

$\mathrm{Na}$ categoria temática práticas corporais verificou-se que as intervenções direcionadas para o corpo possibilitaram desenvolver nos idosos a consciência corporal, assim a noção de corporeidade que integra aspectos da saúde integral estava presente nestes estudos. Alívio da dor e melhorias no desenvolvimento de atividades cotidianas foram relatadas pelos participantes destes estudos, isto permite ressaltar que a avaliação da intervenção identificou resultados positivos que apresentaram repercussões na promoção da saúde. Em outro estudo verificou-se que os idosos consideraram importante as práticas corporais para a 
saúde e solicitaram ampliar a frequência semanal (Oliveira, Feitosa, \& Ferreira, 2012).

No contexto internacional, a análise de estudos sobre o uso da yoga em idosos indicou inúmeros benefícios para a saúde integral, o que inclui o desenvolvimento de mobilidade e flexibilidade do corpo, satisfação com a vida, a redução de estresse, de tensões e de sintomas de ansiedade e depressão (Mooventhan \& Nivethitha, 2017). Carvalho e Nogueira (2016) apresentaram uma discussão teórica entre princípios e ações das práticas corporais e atividade física. Para estes autores, é necessária uma leitura crítica dos princípios epistemológicos para o desenvolvimento de ações congruentes com a proposta de promoção da saúde, assim recomenda-se para o profissional de saúde considerar a participação social e a autonomia das pessoas. Em síntese, as práticas corporais são geradoras de saúde numa perspectiva integral, é importante destacar que as práticas integrativas (yoga, meditação, acupuntura) estão disponíveis no sistema único de saúde do Brasil, isto representa um avanço e um olhar ampliado para as necessidades de indivíduos. Assim, encaminhar idosos participantes de práticas corporais para o desenvolvimento de práticas integrativas representa uma maneira de promover a manutenção destas atividades.

No que se refere a categoria estimulação cognitiva, foi possível identificar as melhorias na função cognitiva da memória de idosos provenientes da participação nas oficinas. Resultado semelhante foi encontro em outro estudo (Almeida, Beger, \& Watanabe, 2007), os participantes relataram os benefícios da memória nas atividades cotidianas, pois o esclarecimento de informações foi complementado com as estratégias de memorização que foram utilizadas nas atividades diárias. Estes estudos demonstram a necessidade de promover a estimulação cognitiva, assim será possível desenvolver no idoso a noção de envelhecimento ativo para que possa reconhecer o seu papel nos diferentes contextos, e para a realização de atividades diárias geradoras de autonomia. Tais propostas de oficinas de memória permitem aos idosos a superação das limitações, quando isso for identificado, pois a plasticidade permite que outras áreas cerebrais executem funções, por outro lado, a manutenção de atividades de leitura e de memorização é benéfica para o cérebro e auxilia os estudos de neurociência.

\section{Considerações Finais}

Nesta revisão sistemática foi possível identificar o panorama dos estudos realizados no contexto brasileiro sobre avaliação de grupos de promoção da saúde no envelhecimento. Nestes estudos destacaram-se a participação feminina, as diferentes ações educativas e formas de avaliação qualitativa e quantitativa. $\mathrm{Na}$ avaliação qualitativa a utlização de grupos focais, e na avaliação quantitativa a verificação de qualidade de vida e estado geral de saúde.

Foram apresentados os resultados de estudos provenientes das categorias de oficinas de educação em saúde, práticas recreativas, práticas corporais e 
estimulação cognitiva. Os resultados positivos apresentados pelos estudos permitem ressaltar a promoção da saúde, considerando a noção de saúde numa perspectiva da integalidade, e os benefícios para os participantes decorrentes das intervenções. Desta forma, recomenda-se para os pesquisadores avaliar os efeitos de intervenções para contribuir com as práticas baseadas em evidências, e especialmente avaliar as dimensões da estrutura, processo e resultados dos programas de promoção da saúde.

O maior número de estudos foi concentrado nas oficinas de educação em saúde, isto indica uma tendência na realização destes estudos, por outro lado, nas outras categorias poucos estudos foram identificados, embora tenham apresentado resultados que contribuem para novas pesquisas. Um aspecto para destaque se refere a realização destes estudos em locais distintos, igreja, praça, grupo de convivência, o que indica a intersetorialidade, mas a integração de diferentes profissionais para a realização destes estudos representa um desafio, assim recomenda-se a realização de estudos por meio da interdisciplinaridade.

Existe um consenso nos resultados dos estudos, indicando que grupos de promoção da saúde contribuem para a socialização das pessoas idosas, permitem a troca de saberes, a diminuição de tempo ocioso, estimulam a participação e o sentimento de pertença na sociedade, e desenvolvem a autonomia. Os resultados das pesquisas evidenciam os benefícios para a saúde integral, isto permite efetivar os princípios e diretrizes das políticas públicas, especificamente, política nacional da promoção da saúde e política nacional do idoso. Diante disto, é possível fomentar o envelhecimento ativo nas ações de promoção da saúde, trata-se de um aspecto gerador de mudanças sociais nas concepções e práticas.

A partir deste panorama, sugere-se que novos trabalhos envolvendo a população idosa sejam apresentados pormeio de avaliações sistemáticas, especificamente recomenda-se a continuidade de estudos sobre práticas recreativas, práticas corporais, e estimulação cognitive, pois representam intervenções fundamentais para a promoção da saúde. Outro ponto se refere a realização de pesquisas referentes à preparação de profissionais da área da saúde para o desenvolvimento de grupos de promoção da saúde, isto pode gerar novas formas de atuação e de pesquisa com o foco na interdisciplinaridade.

A avaliação de programas de promoção da saúde no envelhecimento inclui o compromisso do profissional de saúde e de outras áreas com os aspectos teóricos, práticos e de pesquisa. Em síntese, resultados de avaliações de pesquisas são geradores de programas e políticas públicas, assim, fomentar relatos de experiências e avaliações de programs de intervenção representa uma estratégia útil para o avanço de estudos científicos. O desenvolvimento de intervenções baseadas em evidências contribui para o aprimoramento de práticas e pesquisas.

\section{Referências}

Almeida, M.H.M., Beger, M.L.M., \& Watanabe, H.A.W. (2007). Oficina de memória para idosos: estratégia para promoção da saúde. Interface, comunicação, saúde, educação, 11(22), 271-280. 
Andrade, T.P., Mendonça, B.P.C.K., Lima, D.C., Alfenas, I.C., \& Bonolo, P.F (2012). Projeto Conviver: estímulo à convivência entre idosos do catete. Revista Brasileira de Educação Médica, 36(Supl.1), 81-85.

Andrade, A.N, Nascimento, M.M.P., Oliveira, M.M.D., Queiroga, R.M., Fonseca, F.L.A., \& ... Adami, F. (2014). Percepção de idosos sobre grupo de convivência: estudo na cidade de Cajazeiras-PB. Revista Brasileira de geriatria e gerontologia, 17(1), 39-48.

Andradea, N.B., Canon, M.B.F., Zugman, C.L., Ayres, T.G., Ide, M.G., \& Novelli, M.M.P.C. (2014). Centro de convivência de idosos: uma abordagem de estimulação cognitiva e psicossocial. Cadernos de Terapia Ocupacional da UFSCar, 22(1), 121-128.

Ascari, R.A., Comiran, D.F., Farias, A.A.P., \& Ferreira, L.E. (2015). A percepção do idoso acerca das atividades sociais e saúde. Estudos Interdisciplinares sobre o Envelhecimento, 20(1), 103-119.

Assis, M., Hartz, Z. M.A., \& Valla, V.V. (2004). Programas de promoção da saúde do idoso: uma revisão da literatura científica no período de 1990 a 2002. Ciência \& Saúde Coletiva, 9(3), 557-581.

Baldissera, V.D.A., \& Bueno, S.M.V. (2012). O lazer e a saúde mental das pessoas hipertensas: convergência na educação para a saúde. Revista da Escola de Enfermagem da USP, 46(2), 380-387.

Bardin, L. (2002). Análise de conteúdo. Lisboa: Edições 70.

Barros, M.M.L.D. (2006). Trajetória dos estudos de velhice no Brasil. Sociologia, problemas e práticas, 52,109-132.

Bohm, V. (2013). Envelhecendo com apetite pela vida: interlocuções psicossociais. In S.S. Santos, \& A.C. Carlos (Orgs.). Do casulo para o vôo: o desafio do trabalho com cuidadoras de idosos (p. 129-147). Petrópolis, RJ: Vozes.

Borges, L.M., \& Seidl, E.M.F. (2013). Efeitos de intervenção psicoeducativa sobre a utilização de serviços de saúde por homens idosos. InterfaceComunicação, Saúde, Educação, 17(47),777-788.

Borges, G.M., Campos, M.B., \& Silva, L.G.C. (2015). Transição da estrutura etária no Brasil: oportunidades e desafios para a sociedade nas próximas décadas. In: L.G. Ervatti, M.G. Borges, \& A.P. Jardim (Orgs.). Mudança Demográfica no Brasilno início do século XXI: subsídios para as projeções da população (p. 138-151). IBGE: Rio de Janeiro.

Bottcher, L.B. (2019). Atividade física como ação para promoção da saúde: um ensaio crítico. Revista Eletrônica Gestão \& Saúde, 98-111.

Brasil (2006). Portaria $n^{\circ} 2.528$, de 19 de outubro de 2006. Dispõe sobre a Política Nacional de Saúde da Pessoa Idosa. Ministério da Saúde.Brasília: DF.

Brasil (2012). Glossário temático: gestão do trabalho e da educação na saúde. Ministério da Saúde. Secretaria Executiva de Gestão do Trabalho e da Educação na Saúde. 2 a ed. Brasília, DF. 
Brasil (2014). Portaria n.2446, de 11 de Novembro de 2014. Redefine a Política Nacional da Promoção da Saúde. Ministério da Saúde. Brasília: DF.

Carmagnanis, F. (2016). "Jovens há mais tempo". In: M. Goldenberg (Org.). Velho é lindo (p. 219-244). Rio de Janeiro, RJ: Civilização Brasileira.

Carvalho, F.F.B., \& Nogueira, J.A.D. (2016). Práticas corporais e atividade física na perspectiva da promoção da saúde na atenção básica. Ciência \& Saúde Coletiva, 21(6), 1829-1838.

Carvalho, K.M., Silva, C.R.D.T., Figueiredo, M.L.F., Nogueira, L.T., \& Andrade, E.M.L.R. (2018). Intervenções educativas para promoção da saúde do idoso: revisão integrativa. Acta Paulista de Enfermagem, 31(4), 446-454.

Castro, M.R., Lima, L.H.R., \& Duarte, E.R. (2016). Jogos recreativos para a terceira idade: uma análise a partir da percepção dos idosos. Revista Brasileira de Ciências do Esporte, 38(3), 283-289.

Cavalcante, R.M.F., Dantas, D.S., Araújo, D.N., Magalhães, P.A.F., \& Neves, M.T.S. (2015). Contribuições de um Grupo da Terceira Idade para a saúde das Idosas Participantes. Revista Brasileira de Ciências da Saúde,19(1), 11-18.

Chang, K.S., Tsai, W.H., Tsai, C.H., Yeh, H.I., Chiu, P.H., Chang, Y.W., ... \& Lee, S.C. (2017). Effects of Health Education Programs for the Elders in Community Care Centers e Evaluated by Health Promotion Behaviors. International Journal of Gerontology, 11, 109-113.

Costa, E.M., Rabelo, A.R., \& Lima, J.G. (2014). Avaliação do papel do farmacêutico nas ações de promoção da saúde e prevenção de agravos na atenção primária. Revista de Ciências Farmacêuticas Básica e Aplicada, 35(1), 8188.

Czeresnia, D. (2003). Promoção da saúde: conceitos, reflexões, tendências. Rio de Janeiro: Fiocruz.

Debert, G.G. (2012). A reinvenção da velhice: socialização e processos de reprivatização do envelhecimento. São Paulo: Editora da Universidade de São Paulo- Fapesp.

Donabedian, A. (1984). La calidad de la atención médica: defin- ición y métodos de evaluación. México: La Prensa Mexicana.

Donabedian, A. (1997). The quality of care: How can it be as- sessed? Archives of Pathology \& Laboratory Medicine Online, 121(11): 1145-1150.

Freitas, M.C., Queiroz, T.A., \& Sousa, J.A.V. (2010). O significado da velhice e da experiência de envelhecer para os idosos. Revista da Escola de Enfermagem da USP, 44( 2), 407-412.

Freitas, M.F.Q. (2013). Psicologia na comunidade, psicologia da comunidade e psicologia (social) comunitária: práticas da psicologia em comunidade nas décadas de 1960 a 1990, no Brasil. In: R. Campos (Org.), Psicologia Social Comunitária: da solidariedade à autonomia (p. 44-65). Petrópolis, RJ: Vozes.

Góis, C.W.D.L. (2008). Saúde comunitária: pensar e fazer. São Paulo: Hucitec. 
Goldenberg, G. M. (2014). A bela velhice! Rio de Janeiro: Record.

Gonçalves, C.D. (2015). Envelhecimento bem-sucedido, envelhecimento produtivo e envelhecimento ativo: reflexões. Estudos Interdisciplinares sobre o Envelhecimento, 20(2), 645-657.

Instituto Brasileiro de Geografia e Estatística (2013). Projeções da População Brasil e Unidades da Federação. Rio de Janeiro: IBGE. Brasil.

Janini, J.P., Bessler, D., \& Vargas, A.B. (2015). Educação em saúde e promoção da saúde: impacto na qualidade de vida do idoso. Saúde debate, 39(105), 480-490.

Lane, S.T.M. (2001). O processo grupal. In: S.T.M. Lane, \& W. Codo (Orgs.). Psicologia Social: o homem em movimento (p. 78-98). São Paulo: Brasiliense.

Leite, M.T., Winck, M.T., Hildebrandt, L.M., Kirchner, R.M., \& Silva, L.A.A. (2012). Qualidade de vida e nível cognitivo de pessoas idosas participantes de grupos de convivência. Revista Brasileira de Geriatria e Gerontologia,15 (3), 481-492.

Martin-Baró, I. (1989). Sistema, grupo y poder. San Salvador: UCA.

Monteleone, T.V., \& Witter, C. (2017). Prática baseada em evidências em Psicologia e idosos: conceitos, estudos e perspectivas. Psicologia: Ciência e Profissão, 37(1), 48-61.

Mooventhan, A., \& Nivethitha, L. (2017). Evidence based effects of yoga practice on various health related problems of elderly people: a review. Journal of Bodywork and Movement Therapies, 21(4), 1028-1032.

Moreno, N.L., \& Tsukamoto, M.H.C. (2018). Influências da prática da ginástica para todos para a saúde na velhice: percepções dos praticantes. Conexões: educação física, esporte e saúde, 16(4), 468-487.

Nascimento, E.D.S., Branco, M.P.F.C., Moreira, A.K.F., \& Hazime, F.A. (2012). Os efeitos do lian gong em hipertensos assistidos em unidade de saúde da família do município de Parnaíba, Piauí. Revista Brasileira de Promoção da Saúde, 25(4), 435-444.

Nogueira, A.L.G., Munari, D.B., Santos, L.F., Oliveira, L.M.A.C., \& Fortuna, C.M. (2013). Fatores terapêuticos identificados em um grupo de promoção da saúde de idosos. Revista da Escola de Enfermagem da USP, 47(6), 1350-1356.

Oliveira, B.N., Feitosa, W.G., \& Ferreira, H.S. (2012). Análise da percepção dos idosos integrantes de grupo de práticas corporais na atenção primária: aspectos motivacionais e o fazer profissional. Motrivivência, XXIV (38), 149-158.

Oliveira, R.C.S., Scortegagna, P.A., \& Oliveira, F.S. (2015). Universidade aberta para a terceira idade: o idoso como protagonista na extensão universitária. In: R.C.S. Oliveira, \& P.A. Scortegagna (Orgs.). Extensão universitária: perspectivas e ações para a terceira idade, (p. 2-38). Ponta Grossa: Editora UEPG.

Oliveira, T.R.P.R., Mattiloli, C.D.P., Barcelos, B.J., Horta, N.C., \& Lacerda, T.T.B. (2017). Promoção da saúde e interdisciplinaridade na rede de atenção ao idoso. Geriatrics Gerontology and Aging, 11(4), 182-188. 
Organização das Nações Unidas (2016). População idosa mais do que dobrará até 2050; especialista da ONU pede foco em direitos. Disponível em: <https://nacoesunidas.org/populacao-idosa-mais-do-que-dobrara-ate-2050especialista-da-onu-pede-foco-em-direitos/>. Acesso em 17 março de 2017.

Organização Mundial da Saúde (2005). Envelhecimento ativo: uma política de saúde. Brasília: Organização Pan-Americana da Saúde.

Paula, G.R., Souza, B.N., Barbosa, M.A., Brasil, V.V., \& Oliveira, L.M.A.C. (2016). Qualidade de vida para avaliação de grupos de promoção da saúde. Revista Brasileira de Enfermagem, 69(2), 242-249.

Pedrosa, P.I.S. (2004). Perspectivas na avaliação em Promoção da Saúde: uma abordagem institucional. Ciência \& Saúde Coletiva,9(3), 617-626.

Peyton, C.G., Huang, Y., Syvaoja, K., \& Lohman, H.L. (2019). Aging well: health promotion and disease prevention. In: H.L. Lohman, S. Byers-Connon, \& R.L. Padila (Orgs.). Occupational Therapy whith Elders, 4 a ed (p. 51-68). Mosby.

Ribeiro, M.S., \& Faustino, A.M. (2013). Ações de promoção da saúde para pessoas idosas no Brasil e América Latina: revisão integrativa da literatura. Revista Eletrônica Gestão \& Saúde, 4(3), 1177-1196.

Sampaio, R.F., \& Mancini, M.C. (2007). Estudos de revisão sistemática: um guia para síntese criteriosa da evidência científica, Revista Brasileira de Fisioterapia,11(1), 83-89.

Santos, L.M., Ros, M.A., Crepaldi, M.A., \& Ramos, L.R. (2006). Grupos de promoção à saúde no desenvolvimento da autonomia, condições de vida e saúde. Revista de Saúde pública, 40(2), 346-352.

Sato, A.T., Batista, M.P.P., \& Almeida, M.H.M. (2014). "Programas de estimulação da memória e funções cognitivas relacionadas": opiniões e comportamentos dos idosos participantes. Revista de Terapia Ocupacional da Universidade de São Paulo, 25(1), 51-59.

Silva, E.A.R.D., \& Elali, G.A. (2015). O papel das praças para o envelhecimento ativo sob o ponto de vista dos especialistas. Pesquisas e Práticas Psicossociais, 10(2), 382-396.

Sousa, L.M., \& Assis, M. (2012). Educação popular em saúde e grupos de idosos: revisão sobre princípios teórico-metodológicos das ações educativas em promoção da saúde. Revista de Atenção Primária à Saúde, 15(4),443-453.

Toldrá, R.C., Cordone, R.G., Arruda, B.A., \& Souto, A.C.F. (2014). Promoção da saúde e da qualidade de vida com idosos por meio de práticas corporais. O Mundo da Saúde, 38(2), 159-168.

Trilico, M.L.C., Oliveira, G.R., Kijimura, M.Y., \& Pirolo, S.M. (2015). Discursos masculinos sobre prevenção e promoção da saúde do homem. Trabalho, Educação, e Saúde, 13(2), 381-395.

Wichmann, F.M.A., Couto, A.N., Areosa, S.V.C., \& Montanés, M.C.M. (2013). Grupos de convivência como suporte ao idoso na melhoria da saúde. Revista Brasileira de Geriatria e Gerontologia,16(4),821-832. 
Yabuuti, P.L.K., Jesus, G.M., Buratti, A., Bassani, G.A., Castro, H., Pereira, J.S., \&...Gonçalves, I.O. (2019). O exercício físico na terceira idade como instrumento de promoção da saúde. Revista Eletrônica Acervo Saúde, 11(6), 1-10. 